\title{
A função da biblioteca na escola
}

\author{
Luciana Mendes Ferreirai
}

\begin{abstract}
RESUMO:
Analisa as bibliotecas escolares no contexto histórico para compreender sua conceituação e aceitação por parte da comunidade escolar. Utiliza como metodologia a pesquisa bibliográfica para identificar na literatura da área a concepção de biblioteca escolar ao longo da história e o reflexo no desempenho da sua função na atualidade. Sugere a integração da biblioteca escolar através do planejamento pedagógico, respeitando sua autonomia educativa e formativa, e do envolvimento com os demais setores da escola. Deixando notório que a biblioteca alcança um território ainda pouco explorado pela formalidade do ensino regular contribuindo para a aprendizagem autônoma e prazerosa.
\end{abstract}

Palavras-chave: Biblioteca escolar. História da biblioteca escolar. Função da biblioteca escolar.

\section{The library function at school}

\begin{abstract}
:
Analyzing school libraries in the historical context is fundamental to understanding their conceptualization and acceptance by the school community. Based on the phenomenological reasoning, in which the object is as the subject perceives it, an analytical bibliographical research was proposed, to reflect on the conception of school library throughout history and the reflection on the performance of its function in the present time. It suggests the integration of the school library through pedagogical planning, respecting its educational and formative autonomy, and its involvement with other sectors of the school. Noting that the library reaches a territory still little explored by the formality of regular education contributing to autonomous and pleasurable learning.
\end{abstract}

Keywords: School library. History of the school library. Function of the school library.

Data de submissão: 14/12/2017 - Data de aprovação: 26/03/2018

\footnotetext{
' Especialista em Marketing e Comunicação pela UniBH; Bacharel em Biblioteconomia pela UFMG; email: lumendes.lum@gmail.com.
} 


\section{INTRODUÇÃO}

Com base nas publicações científicas é possível afirmar que a biblioteca escolar foi historicamente negligenciada. Isto deve-se em parte a precariedade do sistema educacional, uma vez que a biblioteca escolar é um instrumento de apoio ao processo de ensino e aprendizado; em outra, pela ausência de implicações práticas no aprendizado e desenvolvimento social que justificassem precisamente sua função análoga à educação formal, perpetuando a condição histórica de biblioteca como mero cenário erudito, ou espaço recreativo adicional. Em detrimento, fez-se necessário a popularização e organização da educação para que a biblioteca pudesse se estabelecer.

Em sua trajetória, as bibliotecas escolares são justificadas pela facilitação do acesso a conteúdos pedagógicos, pelo apoio ao desenvolvimento da linguagem e ao ensino, pela disponibilização de recursos para o desenvolvimento pessoal e social, e pela conservação e difusão do ensino tradicional e da cultura dominante. Não há, portanto, definição das funções exercidas pelas bibliotecas escolares para o atendimento das demandas de informação cabíveis na missão, objetivos e valores próprios da biblioteca na promoção da educação de modo independente.

O presente artigo propõe a compreensão das implicações da concepção de biblioteca escolar, herdada de sua trajetória histórica, no desenvolvimento da sua função no contexto atual. Para tanto utilizou-se da pesquisa bibliográfica como procedimento técnico cujo resultado serviu para alcance dos objetivos propostos.

O conhecimento do estabelecimento histórico da biblioteca como instituição de ensino confirma a hipótese de que a ausência de práticas efetivas características do modelo de aprendizado que se propõe na biblioteca escolar, permitiu que esta fosse diluída no sistema educacional do qual herdou a obsolescência, e que por essa razão precisa de um novo posicionamento baseado no entendimento do contexto social atual. Além disso, as mudanças ocorridas no perfil do usuário nem sempre impactaram mudanças correspondentes nas bibliotecas, o que constitui um erro grave para uma instituição social.

É importante que a biblioteca ofereça mais que um acervo atualizado e informatizado, e tecnologias de informação. É necessário que o potencial formativo da biblioteca tenha impacto na comunidade escolar. Tendo em vista a configuração das estratégias de ensino atuais para o alcance desse objetivo é fundamental o 
envolvimento com os demais setores de apoio ao ensino extraclasse. Sugere a integração da biblioteca escolar através do planejamento pedagógico, respeitando sua autonomia educativa e formativa, e do envolvimento com os demais setores da escola. Deixando notório que a biblioteca alcança um território ainda pouco explorado pela formalidade do ensino regular contribuindo para a aprendizagem autônoma e prazerosa.

Nos últimos anos tem se intensificado o apelo da classe bibliotecária para o reconhecimento da importância da biblioteca escolar, no entanto, faz-se necessário o delineamento da sua função para seu desenvolvimento. É crucial que ao invés de proclamada, a função seja exercida.

\title{
2 A BIBLIOTECA ESCOLAR NA HISTÓRIA
}

No decorrer da história, as bibliotecas foram incumbidas de funções importantes no contexto social de cada época. As primeiras bibliotecas tinham a função de preservar o conhecimento e a cultura para o desenvolvimento do saber técnico e científico. Em meio a disputas de impérios por volta do ano 1000 a.C. ampliaram seu acervo protegendo a produção documental de caráter burocrático. Após o Renascimento, as bibliotecas alcançaram o status de templos do saber.

De acordo com Viana (2014, p. 13)

\begin{abstract}
No cenário europeu renascentista, a biblioteca passa por um processo de laicização cada vez mais nítido. Do final do século XVI ao momento presente, sua história assentou-se, gradativamente e simultaneamente, em transformações que, além da laicização, incluíram outras características fundamentais: democratização, especialização e socialização.
\end{abstract}

Atendendo ao aspecto democrático, a biblioteca pública se consolidou após a Revolução Francesa, estimulada pelo apelo de biblioteca como espaço público e universal de Gabriel Naudé. E através dos conceitos da Revolução Industrial esforçou-se para atender a educação da massa trabalhadora. Nessa perspectiva, expandiu sua função no último século para disseminação da informação e promoção de lazer, passando, portanto, por quatro estágios de ênfase na sua função: educacional, no século XIX; cultural, no início do século XX; recreacional, século XX; e, informacional, nas décadas de 1960 e 1970. (VIANA, 2014) 
Sobre a biblioteca escolar sabe-se pouco quanto a sua origem. A especialização proporcionou o desenvolvimento de diferentes tipos de biblioteca com objetivos específicos, destacando-se a biblioteca escolar, que surge com o objetivo de conservar os materiais utilizados em sala de aula. Segundo Viana (2014, p. 13)

\begin{abstract}
Em 1860, especificamente no contexto francês, os prefeitos eram orientados a instalar 'uma pequena biblioteca-armário, destinada à conservação dos livros, dos cadernos e dos quadros impressos para uso da escola'. Com efeito, a criação da biblioteca-armário nas escolas tinha o intuito de reunir e preservar os livros, com vistas à ampliação de seu uso pelos alunos. Portanto, o caráter democrático da biblioteca escolar circunscrevia-se à garantia de acesso aos livros pelos estudantes.
\end{abstract}

Até a virada do século $X X$, as bibliotecas escolares possuíam natureza informal. Em seu artigo, Cole (1959) descreve o desenvolvimento das bibliotecas escolares norte americanas em quatro estágios. O primeiro estágio, ainda teórico, na segunda metade do século XVIII associada à ideia do que temos hoje como biblioteca universitária. O segundo estágio resultou do estabelecimento de algumas bibliotecas escolares sob a supervisão de um funcionário da escola, na metade da década de 1830 até meados de 1870. No terceiro estágio a biblioteca passou a ser entendida como auxiliadora no processo de ensino e como uma fonte de leitura e prazer, além de passar a contar com o trabalho de um bibliotecário, embora dificilmente este tivesse as qualificações para o exercício da função na época. Sobre o quarto estágio, Cole (1959) informa em seu artigo que figuras importantes dos Estados Unidos deram grande contribuição ao estudar métodos educacionais no exterior.

No Brasil, desde a segunda metade do século XVI até a segunda metade do século XVIII, as "bibliotecas jesuítas deram base à formação intelectual dos jovens brasileiros. [...] já em fins do século XVI havia sido instalada uma biblioteca em Salvador; a biblioteca do colégio de Santo Alexandre do Pará, em 1760" (VIANA, 2014, p. 23). Em 1772, embora o ensino tenha se tornado oficialmente público, havia total precariedade. Pelo regulamento n. $\stackrel{8}{8}$, de 31 de janeiro de 1838, D. Pedro II institui a estrutura administrativa e pedagógica do colégio, sendo o primeiro documento brasileiro que explicita a existência e as características da biblioteca escolar. No Brasil República, articulou-se por uma nova cultura escolar. Com o fim 
do modelo escravocrata acreditava-se que a educação era o meio de ascensão social (VIANA, 2014, p. 29).

A preocupação do sistema de ensino era a simples conservação e difusão do ensino tradicional e da cultura dominante.

\footnotetext{
De modo geral, o desenvolvimento de bibliotecas escolares se deu atrelado ao movimento de expansão do ensino. Para Gomes (1983, p. 65), a implementação do currículo enciclopédico pode ter motivado a criação de bibliotecas escolares tendo em vista atender às novas disciplinas (VIANA, 2014, p. 29).
}

Com os impactos da Primeira Guerra Mundial e a preocupação com o alto nível de analfabetismo, observou-se a reorganização da prática escolar e a centralidade do aluno no processo educacional. Nessa perspectiva, a educação alcançou maior importância, inclusive política, e a leitura passou a ser vista como instrumento de aprendizado e de prazer.

No início de 1990, as bibliotecas escolares começaram a ser incentivadas por autoridades governamentais e associações profissionais conforme Clyde (1981).

A Secção de Bibliotecas Escolares da American Library Association (ALA) foi criada em 1914, que mais tarde se tornou a Associação Americana de Bibliotecas Escolares.

Em 1920, o relatório da Commission on Library Organization and Equipment da National Education Association e da North Central Association of Colleges and Secondary Schools publicado pela ALA com o título Standard Library Organization and Equipment for Secondary Schools of Different Size se tornou o primeiro documento sobre padrão de bibliotecas escolares. Dizia o documento que pela primeira vez a biblioteca era vista como o coração do ensino médio.

Novas abordagens sobre o ensino levaram a outras formas de pensar a biblioteca escolar. As principais concepções envolviam, segundo Clyde (1981, p. 239, tradução nossa) "a ênfase nas diferenças individuais das crianças e o aprender como um processo que envolve a própria iniciativa da criança, tem como resultado um papel mais central e crucial para a biblioteca." Quando os trabalhos de Maria Montessori, as teorias de John Dewey e de psicólogos educacionais como William Janets e William McDougall ganharam força, os "livros e bibliotecas foram vistos como importantes [...] como forma de permitir que as crianças desenvolvam suas próprias experiências" (CLYDE, 1981, p. 239, tradução nossa). Assim, o processo de 
aprendizado centrado no aluno e por isso personalizado, e de maneira autônoma recebe ênfase nas bibliotecas escolares.

\section{A APRENDIZAGEM NA BIBLIOTECA E A BIBLIOTECA COMO APOIO AO PROCESSO DE APRENDIZADO}

A biblioteca escolar é um instrumento educativo com missão, objetivos claros e métodos próprios através dos quais desenvolve ações que contribuem para o desenvolvimento educacional e formação social dos indivíduos. É autônoma em uma perspectiva educativa e formativa, não obstante seja necessário o alinhamento com a proposta pedagógica da instituição a que pertence para que o seu papel seja efetivo.

A biblioteca da escola deve ser compreendida sob um aspecto funcional, desassociada de seu conceito arcaico de lugar ou reunião de coleções, ou ainda a modelos de comportamento. Para isso, é fundamental o delineamento da sua função que é parâmetro para a realização de projetos conjuntos com os diversos setores da escola, e que implica em alterações na sua gestão, nos seus serviços, e principalmente no modo como a biblioteca é vista pelo usuário, ocasionando a ruptura com antigos padrões.

Assim, a biblioteca assume seu papel como núcleo de aprendizado. Sua relação com a escola não se dá como parte de um todo fracionado, mas como um aparelho formativo completo que em junção com outros tem o objetivo de promover o aprendizado em suas múltiplas facetas. Cada componente da estrutura pedagógica possui suas competências de interferência e campo de ação. A função que a biblioteca escolar exerce, ou deveria exercer, é a dinamização do processo de aprendizado.

Tratar do aprendizado na biblioteca e da biblioteca como apoio ao processo de aprendizado requer diferenciação conceitual. De ambas as formas o aprendizado deve acontecer. A primeira de forma mais autônoma enquanto a segunda inteiramente dependente do currículo e da prática pedagógica. É necessário que as atividades realizadas e serviços prestados pela biblioteca estejam todos em consonância com o projeto pedagógico.

Velho et al (2002 apud RAMOS, 2009, p. 93) faz uma contribuição importante na pesquisa sobre a história das bibliotecas escolares. Para eles a 
[...] precursora: a Biblioteca Escolar de Aristóteles (por volta de 540 a. C.), [...] teria 'mudado a própria história da humanidade', uma vez que teria auxiliado Demétrio de Farelo e Ptolomeu a fundarem o Museu e a Biblioteca de Alexandria.

Ao citar a biblioteca de Aristóteles, Velho (2002 apud RAMOS, 2009) faz menção à função exercida desde os primórdios pela biblioteca escolar, antes ainda do seu surgimento. A função de contribuir para o aprendizado mesmo que o lugar ou acervo não tivessem sido pensados para tal tarefa, mas com o olhar unicamente voltado para o usuário e sua necessidade de aprendizado através do atendimento de referência na orientação à pesquisa. Assim, o entendimento de biblioteca como lugar de aprendizado é anterior ao entendimento de biblioteca como auxiliadora do processo de aprendizado. Complementarmente, a biblioteca deve se ocupar em não somente atender a demanda do usuário, mas oferecer possibilidades de aprendizado e aguçar a curiosidade para além do currículo escolar.

É importante enfatizar que a metodologia de ensino utilizada nas bibliotecas é distinta da utilizada em sala de aula, o que torna o apoio ao ensino tão importante. Colabora para esse entendimento a descrição das funções da biblioteca presente no projeto 'Newton gostava de ler' da Rede de Bibliotecas Escolares de Portugal:

\begin{abstract}
A biblioteca promove o trabalho de pesquisa e produção documentais em diferentes suportes e linguagens, facilita a aquisição de competências de informação, estimula o prazer da leitura e desenvolve hábitos de trabalho conducentes à autonomia e gosto pela aprendizagem ao longo da vida. As bibliotecas escolares desempenham, deste modo, uma função indispensável, quer no contexto das atividades disciplinares, quer no de projetos de natureza interdisciplinar ou transdisciplinar, quer ainda na ocupação dos tempos livres, devendo mobilizar-se os seus recursos em todas as situações educativas proporcionadas aos alunos (PORTUGAL. Ministério da Educação, 2011, p. 2).
\end{abstract}

O aluno deve ter facilidade ao transitar entre o conhecimento oferecido pela escola em seus múltiplos espaços, seja em sala de aula ou na ambiência da biblioteca. Embora aplicado de diferentes modos, deve haver consistência de conteúdo por meio da coordenação de ações que integrem os assuntos ministrados pelos docentes e os materiais e atividades da biblioteca, por exemplo.

O conceito de biblioteca híbrida sugere a mescla de suportes de informação, enquanto a proposta de biblioteca como Centro de Recursos para a Aprendizagem requer a especialização para uso destas ferramentas. O que se propõe, no entanto, é a biblioteca escolar em um terceiro estágio, integrada aos demais setores da 
escola para a ampliação de recursos tecnológicos e de informação e intensificação do ensino.

\title{
4 A BIBLIOTECA ESCOLAR COMO ESPAÇO SOCIAL E A DEMOCRATIZAÇÃO DO ENSINO
}

O conceito de espaço social está associado à multidimensionalidade do ambiente onde as relações sociais se efetivam pela interação entre os atores sociais por meio da linguagem. Segundo o sociólogo Bourdieu (1986, apud CATANI, 2011) o campo social determina um espaço simbólico onde são realizadas trocas entre agentes. Sendo assim a biblioteca é um espaço social.

A biblioteca é um campo social e democrático. Viana (2002, p. 353) destaca a leitura como método para a inclusão social na história das bibliotecas escolares.

\begin{abstract}
As mudanças desenvolvidas em torno da biblioteca escolar foram marcantes e encontraram espaço nas próprias necessidades de leitura que se delineavam no contexto nacional, em que decifrar o código da escrita passou a ser preciso para que as pessoas pudessem lidar com a profusão de materiais impressos, que demarcavam os usos nos universos urbano, social e do trabalho. Logo, foi fundamental o papel da escola para constituir leitores numa cultura urbana em que signos escritos se multiplicavam [...]
\end{abstract}

Todavia, para a democratização da informação não é bastante o acesso, "é preciso uma perspectiva que, para além do direito de acesso, contemple o direito de saber informar-se, de que sujeitos se apropriem de informação cultural em perspectiva crítica e criativa [...]" (VIANA, 2014, p. 14).

O letramento informacional é um recurso para a democratização da informação e afirmação do trabalho desenvolvido pela biblioteca. Tendo como base o currículo é possível desenvolver atividades na biblioteca que propiciem a abertura para o aprendizado extraclasse e o desenvolvimento das habilidades e competências necessárias para o aprendizado ao longo da vida.

Afirma Bernardes (2003, p. 87) que

Pensar a leitura e a escrita na biblioteca implica, em contrapartida, ultrapassar a ideia de que consiste essa instância num edifício, numa sala de leitura, numa mera coleção de livros enfileirados numa estante ou digitalizados nos provedores informáticos. Uma biblioteca, em qualquer esfera da atividade humana, emerge, com base nos pressupostos baktinianos, como um espaço discursivo por excelência, o qual só adquire pleno sentido pelo trabalho linguístico de seus leitores-escritores. 
A concepção de biblioteca como espaço, sem dúvida, impede o entendimento da sua função, do trabalho desempenhado pelos indivíduos envolvidos, das atividades realizadas e dos serviços prestados pela biblioteca, cujo objetivo principal deve ser o atendimento ao usuário para o cumprimento de seu papel social.

As formas de acesso à informação e o modo como é disponibilizada alteraram as formas de aprendizado e o comportamento do usuário. O desafio da biblioteca hoje é ser um espaço para a construção do conhecimento interdisciplinar e interligado. A biblioteca precisa adaptar-se, abrir-se para novas formas de aprendizado, de interações entre os usuários e as tecnologias. A biblioteca escolar deste século deve compreender a imersão do usuário na diversidade de informações e sua interação em uma rede de comunicação. Motivados no ambiente educacional pela interdisciplinaridade, transdisciplinaridade e colaboração.

O quadro 1 faz um comparativo das abordagens de biblioteca como lugar e como função.

\section{Quadro 1 - Perspectiva de lugar e função da biblioteca escolar}

\begin{tabular}{|c|c|}
\hline $\begin{array}{c}\text { BIBLIOTECA } \\
\text { (ABORDAGEM DE LUGAR) }\end{array}$ & $\begin{array}{c}\text { BIBLIOTECA } \\
\text { (ABORDAGEM DE FUNÇÃO) }\end{array}$ \\
\hline $\begin{array}{l}\text { LOCAÇÃO DO ESPAÇO } \\
\text { Exige a presença impreterivelmente e } \\
\text { rigorosamente de alunos no espaço da } \\
\text { biblioteca, usando de estatística para avaliar } \\
\text { frequência. }\end{array}$ & $\begin{array}{l}\text { ESPAÇO EXPANDIDO } \\
\text { O espaço expandido considera os demais } \\
\text { espaços da escola como membros de um } \\
\text { circuito cujos interesses e finalidades são } \\
\text { recíprocos. Considera a frequência à } \\
\text { biblioteca um indicador da necessidade de } \\
\text { informação engatilhada pelo processo } \\
\text { educativo e/ou desenvolvimento } \\
\text { intelectual, bem como local agradável para } \\
\text { a realização de tarefas. Sendo } \\
\text { considerada de maior valor a presença } \\
\text { voluntária. }\end{array}$ \\
\hline $\begin{array}{l}\text { BIBLIOTECÁRIO } \\
\text { TRABALHO OPERACIONAL } \\
\text { Profissional que se ocupa das atividades } \\
\text { técnicas, atendimento do usuário para } \\
\text { empréstimos e devoluções. Passivo a } \\
\text { proposta educacional. }\end{array}$ & 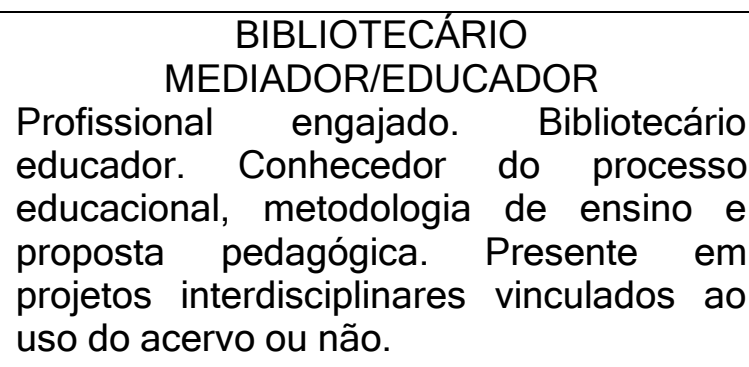 \\
\hline
\end{tabular}




\section{ACERVO CENTRALIZADO}

O uso do acervo depende exclusivamente do nível de interesse do usuário na busca do material. Considerando a facilidade com que a geração de nascidos digitais acessa a informação há uma grande perda na funcionalidade do acervo. Tratamento direcionado para a organização.

AVALIAÇÃO QUANTITATIVA Relatórios estatísticos servem de base para as tomadas de decisão.

\section{ACERVO DESCENTRALIZADO}

A disponibilização do material estimula (com auxilio do educador) a investigação e seu uso. Além disso, aumenta a visibilidade dos materiais que a biblioteca dispõe. Tratamento direcionado para o uso.

\section{AVALIAÇÃO QUALITATIVA}

A avaliação quantitativa é muito importante para a avaliação das decisões tomadas e ações realizadas. No entanto, o viés humano e social da área de atuação define a avaliação qualitativa como primordial para a verificação do alcance dos objetivos. Embora subjetiva é possível analisar 0 desenvolvimento do aluno através do uso frequente e substancial do acervo além do seu desenvolvimento e aproveitamento na disciplina.

\section{BENEFÍCIO INTANGÍVEL}

Neste sentido a visão simbólica e histórica da biblioteca, da leitura e do livro é o elemento básico que serve de justificativa para o uso do espaço e utilização dos itens do acervo.

\section{BENEFÍCIO "TANGÍVEL"}

O benefício da utilização é perceptível embora de difícil mensuração. conhecimento é examinado em seu processo acumulativo. A ideia de leitura para "viajar" e aprender, torna-se um discurso subjetivo, sendo a proposta do projeto educativo maior que um anúncio de benefícios, mas um acompanhamento prático.

Fonte: Autoria própria

O tão proclamado silêncio, que nesse sentido refere-se ao isolamento, sabido que a linguagem é manifesta não somente através da fala, é substituído pelo ruído das interações sociais que nela ocorrem, seja no desenvolvimento de atividades colaborativas ou nas interações através da linguagem.

Se entendemos a linguagem como competência e a língua como habilidade, ou como explica Bernardes (2003, p. 87), a linguagem como atividade, processo criativo, materializado nas enunciações, compreendemos o caráter dialógico e enfatizamos a importância da biblioteca como espaço social propício para o desenvolvimento humano nesse aspecto. Em defesa, faz-se necessário o entendimento de alguns pontos: a leitura como processo dialógico; a biblioteca como espaço de socialização e interação derivada da troca de saberes, do letramento como processo formador ativo alavancado em que o usuário é capaz de impulsionar 
e gerir o próprio aprendizado. A partir de então, podemos entender a biblioteca como um lugar discursivo, pois se entende o uso de seu espaço e existe a apropriação por benefício.

O entendimento da biblioteca escolar e sua função passam basicamente pelo entendimento de que o indivíduo/usuário é influenciado pelo contexto social ao mesmo tempo em que determina este contexto através da ação social coletiva, e essa sociedade dentro do contexto impacta ou deveria impactar o processo educativo/sistema educacional, conforme mostra a figura 1.

Figura 1: Âmbito de influência educacional

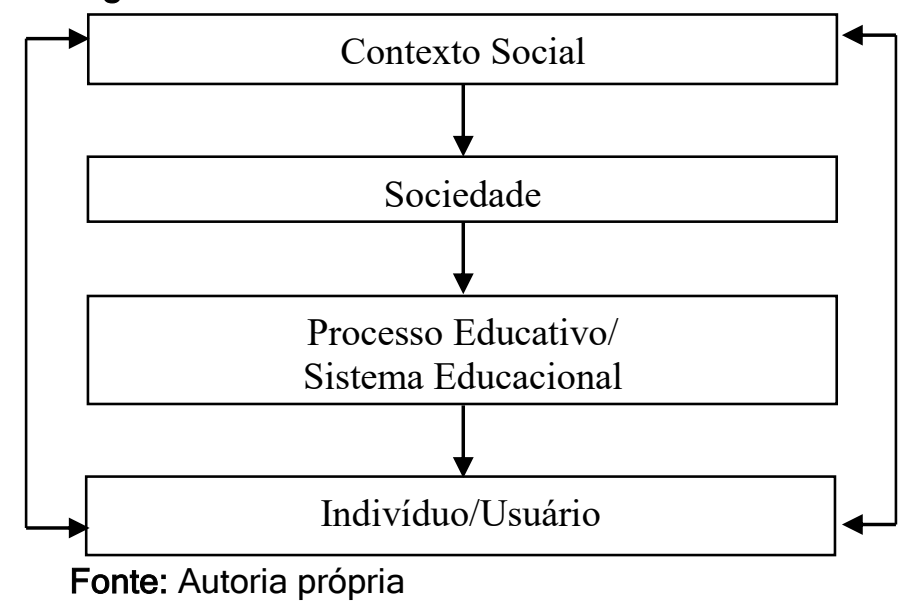

A biblioteca escolar como espaço social propõe o aprendizado através da interação, seja pelo diálogo entre o autor e o leitor na efetivação da leitura ou pela interação dos usuários. Como resultado, a biblioteca moderna requer dinamização. Não obstante, as bibliotecas parque tem tamanha aceitação pelo seu nível de engajamento com os interesses dos usuários.

Quando observamos e acompanhamos as constantes transformações no contexto social, o papel da biblioteca ganha novos contornos. As tecnologias passam a não ter tanta ênfase quanto à capacidade de sua utilização, as atividades assumem outra função que não unicamente a promoção do livro e da literatura, a ambientação da biblioteca é alterada quando entendemos as formas atuais de aprendizado através da interação entre usuários e com os meios para a aquisição de informação. Também o usuário é o agente motivador e principal mentor das mudanças que devem ocorrer na biblioteca escolar para o cumprimento da sua finalidade e adequação a demanda, ainda mais ampla que a necessidade de informação pontual. Assim, o comportamento alterado pelo aperfeiçoamento das relações e dos meios de informação e comunicação exige uma nova postura das Rev. Inf. na Soc. Contemp., Natal, RN, v.2, n1, jan./jun., 2018 | 
instituições. Requer o oferecimento de novos serviços, a ampliação do espaço e a apresentação de novos recursos, criando novas possibilidades de aprendizado.

Essa ampliação do espaço se dá através da interação da biblioteca com os demais setores da escola, dentre eles: os laboratórios de ciências e informática, o auditório, a sala de música, o parque de recreação e a sala de aula, na tentativa de suprir a demanda da multiplicidade de relações sociais e da interdisciplinaridade dos saberes. Assim, mais que promover debates, clubes de leitura, saraus, apresentação de filmes e ações coletivas, que incluam tecnologias de informação e comunicação, é necessário expandir as possibilidades e transpor a passividade diante do processo educacional, propondo o aprendizado não somente através de diversas fontes e canais, como também através dos pares e contribuindo para o desenvolvimento do potencial criativo. Nesse sentido, Morán (2015) afirma que

\begin{abstract}
As metodologias precisam acompanhar os objetivos pretendidos. Se queremos que os alunos sejam proativos, precisamos adotar metodologia em que os alunos se envolvam em atividades cada vez mais complexas, em que tenham que tomar decisões e avaliar os resultados, com apoio de materiais relevantes. Se queremos que sejam criativos, eles precisam experimentar inúmeras novas possibilidade de mostrar sua iniciativa (MORÁN, 2015, p. 17).
\end{abstract}

A biblioteca escolar contemporânea requer um novo modelo de estudo de usuários, que considere a multiplicidade de perfis e os novos hábitos e comportamentos dos indivíduos influenciados pelas novas tecnologias, para a promoção de um ensino personalizado. Além disso, as políticas públicas e a legislação devem proporcionar a base para a ação e manutenção da biblioteca. Para Viana $(2014$, p. 52)

A inação encontra abrigo nas próprias limitações que se impuseram à
biblioteca escolar enquanto problema público, uma vez que, com pesar, é
possível constatar que, se no século XIX biblioteca escolar resumia-se a um
acervo de materiais para leitura, em pleno século XXI o problema público
circunscreve-se de modo semelhante no texto legislativo: a disponibilidade
de recursos informacionais de diferentes ordens, como se o mero
fornecimento de acesso à informação caracterizasse por si só uma
biblioteca escolar.

A informação e a tecnologia não são os elementos centrais da biblioteca escolar. Os usuários são o foco do aperfeiçoamento. Não se quer, no entanto, suprimir a importância das tecnologias, especialmente das tecnologias de informação e comunicação. Ao contrário, fazer entender que estas são tão 
importantes que são extensões de nós mesmos. $E$ que por isso podemos concluir que a mais significativa mudança no sistema 3.0 ou híbrido, seja qual for à nomenclatura que ele receba, é decorrente do seu reflexo na sociedade.

\section{CONSIDERAÇÕES FINAIS}

Através da análise histórica compreende-se que as bibliotecas escolares surgiram principalmente por interesses políticos e foram estabelecidas sem implicações práticas no aprendizado. Primeiro, devido à ausência de um conceito claro de biblioteca escolar, e, por conseguinte, decorrente da ausência de um delineamento claro da sua função.

A biblioteca foi diluída no ambiente escolar e interpretada como um adendo no processo de ensino e aprendizado. Todavia, a biblioteca escolar é anterior à própria instituição escolar e sua função não é apenas a de apoiar o ensino e o aprendizado concretizado em sala de aula. A função da biblioteca escolar é promover novo conhecimento à medida que instiga a curiosidade, a experimentação, a busca.

A função primordial da biblioteca escolar é promover o processo de ensino e aprendizado e auxiliar na formação de indivíduos críticos e de cidadãos conscientes, no aperfeiçoamento pessoal e no envolvimento social. Para isso, é necessário apresentá-los ao mundo e às ferramentas que possibilitem o desenvolvimento de suas competências e habilidades, ademais de envolvê-los com os elementos pertencentes ao seu universo e representativos de uma vida adulta para a concretização do processo autônomo de formação das inteligências. A escola não é um protótipo do mundo, mas um espaço real de interação com o mundo e com o outro.

Quando a biblioteca escolar assume a sua função, ela se afirma como núcleo de ensino e aprendizado autônomo em uma perspectiva educativa e formativa, e permite a integração com o planejamento escolar.

\section{REFERÊNCIAS}

BERNARDES, Alessandra Sexto. Do texto pelas mãos do escritor ao texto nas mãos 
do leitor: pensando a leitura e a escrita na biblioteca. Revista Brasileira de Educação, n. 22, p. 77-88, jan./abr, 2003.

CATANI, Afrânio Mendes. As possibilidade analíticas da noção de campo social. Educação e Sociedade, Campinas, v. 32, n. 114, p. 189-202, jan./mar. 2011.

CLYDE, Laurel A. The magic casements: a survey of school library history from the eighth to the twentieth century. 1981. [788 f.]. Tesis (PhD) - James Cook University, North Queensland, 1981.

COLE, Tom J. The origin and development of school libraries. Peabody Journal of Education, v. 37, n. 2, p. 87-92, Sept. 1959.

MORÁN, José. Mudando a educação com metodologias ativas. In: SOUZA, Carlos Alberto de; MORALES, Ofélia Elisa Torres. Convergências Midiáticas, Educação e Cidadania: aproximações jovens. Ponta Grossa: PROEX/UEPG, 2015. p 15-33. Coleção Mídias Contemporâneas, v. 2.

PORTUGAL. Ministério da Educação. Gabinete da Rede Bibliotecas Escolares. Newton gostava de ler. Lisboa: RBE, 2011.

RAMOS, Cleriston Ribeiro; MUNHOZ, Deise Parula; MUNHOZ, Andreia Parula; WYSE, Thiago Lopes da Silva. Aproximando o aluno da biblioteca escolar por meio do "estímulo entre pares". Biblios, Rio Grande, v. 23, n. 2, p. 93-103, jan./jun. 2009.

VIANA, Lilian. Bibliotecas Escolares: políticas públicas para a criação de possibilidades. 2014. 167 f. Dissertação (Mestrado em Ciência da Informação) Escola de Comunicação e Artes, Universidade de São Paulo, São Paulo, 2014. 